\title{
Phylogenetic analysis of livestock oxacillin-resistant Staphylococcus aureus
}

\author{
Jui-Ming Hsieh ${ }^{\mathrm{a}}$, Ren-Shinn Chen ${ }^{\mathrm{b}}$, Tsung-Yu Tsai ${ }^{\mathrm{c}}$, \\ Tzu-Ming Pan ${ }^{\mathrm{c}}$, Chin-Cheng Chou ${ }^{\mathrm{a}, \mathrm{d}, *}$ \\ ${ }^{a}$ Department of Veterinary Medicine, National Taiwan University, Taipei 106, Taiwan \\ ${ }^{\mathrm{b}}$ Taoyuan County Animal Disease Control Center, Taoyuan 330, Taiwan \\ ${ }^{\mathrm{c}}$ Institute of Microbiology and Biochemistry, National Taiwan University, Taipei 106, Taiwan \\ ${ }^{\mathrm{d}}$ Center for Zoonoses Research, College of Bio-Resources and Agriculture, National Taiwan University, Taipei 106, Taiwan
}

Received 9 March 2007; received in revised form 16 July 2007; accepted 17 July 2007

\begin{abstract}
The aim of this study was to characterize oxacillin-resistant Staphylococcus aureus (ORSA) isolates from livestock environments and meat market workers by molecular epidemiological analysis. Staphylococcal enterotoxin reversed passive latex agglutination (RPLA) and multiplex polymerase chain reactions (PCR) were used to detect enterotoxin-producing $S$. aureus. The molecular genetic similarity of ORSA was also compared by pulse-field gel electrophoresis (PFGE) and multi-locus sequence typing (MLST). A total of 30 ORSA isolates were identified and 27 of these strains were from human sources-a higher contamination potential from human origin in the animal raising and handling field was suspected. The most common type of enterotoxin detected in this study was type B. Regarding the bacterial phylogenetic analysis of ORSA isolates, five major clusters of PFGE patterns were suggested with $>80 \%$ similarity in cluster I. Seven MLST patterns were identified with the most

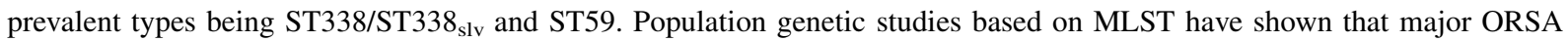
clones have emerged from six clonal complexes (CCs), with CC59 being the dominant one. In conclusion, a high prevalence of

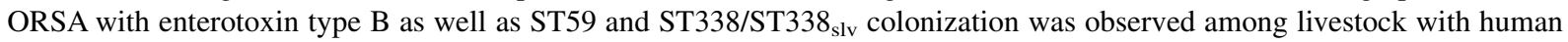
origins in this study. We suggest further tracking and comparing of the epidemiological evidence of community-acquired and hospital-acquired ORSA in human living environments and livestock-producing environments.
\end{abstract}

(C) 2007 Published by Elsevier B.V.

Keywords: Enterotoxin; MLST; ORSA; PFGE; RPLA

\footnotetext{
* Corresponding author. Present address: Department of Veterinary Medicine, National Taiwan University, No. 1, Sec. 4, Roosevelt Rd., Taipei 106, Taiwan. Tel.: +886 233661292 ; fax: +886223630495 .

E-mail address: chouchin@ntu.edu.tw (C.-C. Chou).
}

\section{Introduction}

Staphylococcus aureus is one of the major enterotoxin-producing causative agents responsible for the symptoms of food poisoning, and methicillin- 
resistant $S$. aureus (MRSA) has been identified as a nosocomial pathogen throughout the world (Vandenesch et al., 2003). Since MRSA is highly transmissible in hospitals and usually presents multi-drug resistance patterns, the increase in prevalence of MRSA infections may result in an acceleration of mortality as well as increased medical and human resources costs (Wang et al., 2002a).

MRSA was first reported in the United Kingdom in 1961 and had become a major problem worldwide by the mid-1990s (Ayliffe et al., 1998). MRSA received substantial concern in the United States in 1999 with the report of four fatal cases of community-acquired MRSA (CA-MRSA) infections in infants (CDC, MMWR 1999). Clinical prevalence of MRSA isolates in seven countries in Europe reported levels of over $40 \%$, including Romania (61.4\%), Cyprus (55.6\%), Malta (55.1\%), Portugal (46.6), United Kingdom (43.6\%), Greece (42.1\%) and Ireland (41.8\%) (EARSS Annual Report, 2005). The incidence of hospital-acquired MRSA (HA-MRSA) isolates is higher than $70 \%$ in some Asian countries such as Taiwan, China and Korea (de Sousa et al., 2003; Kim et al., 2003).

Isolation of MRSA from animals was first reported in 1972 following its detection in milk from mastitis cows (Devriese et al., 1972). The role of MRSA in the field of veterinary medicine was unclear and occasional reports have recently been published on MRSA infections in domestic animals including dogs, cats, cattle, sheep, chickens, rabbits and horses (O'Mahony et al., 2005). These observations indicated that some MRSA colonized in a significant proportion of healthy individuals in the community, thereby facilitating disease spread not only from human to human but also from human to animals (Van et al., 2004; Weese et al., 2005). MRSA was also termed as oxacillin-resistant $S$. aureus (ORSA) when oxacillin was used instead of methicillin during bacterial antimicrobial sensitivity screening for anti-beta-lactamase antibiotics in hospitals (McDougal et al., 2003). Accordingly, $S$. aureus isolates from livestock facilities and meat markets were used to characterize types of enterotoxin production and the phylogenetic similarity of ORSA through molecular typing in order to pinpoint site prevalence of ORSA.

\section{Materials and methods}

\subsection{Bacterial isolation and identification}

Bacterial isolates for this study are from (1) our previous investigations (Ma et al., 2006), including isolates from nasal swabs of livestock workers, animal samples from broiler, swine and dairy cow, and livestock environment (Chen, 2005); and (2) nasal swab isolates from 56 and 58 workers of a Taoyuan County local meat market in August 2004 and August 2005, respectively. Human consent forms were filed before sampling livestock and meat market workers.

Sampling procedures for bacterial isolation have been previously reported (Ma et al., 2006). In brief, environmental samples were taken from influent and effluent water, floor surfaces and feed in the livestock housing. Animal samples were collected from broiler cloacae, swine anus, dairy cow udder surface and fecal rectal samples by swabbing with sterile PBS-rinsed cotton swabs. Human samples were collected from workers' nasal cavities with the same technique. All specimens were streaked for isolation onto a BairdParker medium (Difco, Sparks, MD), mixed with eggyolk tellurite emulsion, and also inoculated in brain heart infusion (BHI) broth (Difco, Detroit, MI), incubated at $37^{\circ} \mathrm{C}$.

Staphylococcal isolates were identified by colony morphology, Gram-staining and tube coagulase test supplemented with rabbit plasma (Becton \& Dickinson, Sparks, MD). Four additional ancillary tests, including catalase, aerobic utilization of mannitol, anaerobic utilization of mannitol and anaerobic utilization of glucose were also applied. All processed tests of S. aureus were based on the Bacteriological Analytical Manual of Food and Drug Administration, USA (Bennett and Lancette, 1998). Identification of $S$. aureus was reconfirmed with API kits, of either API STAPH or ID 32 STAPH systems (bioMérieux sa, Marcy l'Etoile, France).

The standard enterotoxin producing strains of $S$. aureus including strain A (BCRC 12657 \& BCRC 13824), strain B (BCRC 12653), strain C (BCRC 12654), strain D (BCRC 12660) and strain E (BCRC 12656) were all purchased as from Bioresource Collection and Research Center at Food Industry Research and Development Institute (Hsinchu, Taiwan). The screening and diagnoses for culture and 
susceptibility testing of ORSA were performed regularly.

\subsection{Susceptibility test for ORSA}

The identified $S$. aureus isolates were screened for oxacillin resistance by an oxacillin screening plate test. S. aureus isolates were cultured in $5 \mathrm{ml}$ BHI broth. Organisms were harvested from the BHI broth to yield at least a turbidity of $0.5 \mathrm{McF}$ arland's standard after $4-6 \mathrm{~h}$ of incubation, then an inoculum of $10^{4} \mathrm{CFU}$ was spotted onto a Mueller-Hinton agar plate (Difco, Cockeysville, MD) supplemented with $4 \% \mathrm{NaCl}$ containing $6 \mu \mathrm{g}$ of oxacillin (Bristol-Myers Squibb, Sermoneta, Italy) per $\mathrm{ml}$. After $24 \mathrm{~h}$ of incubation at $35{ }^{\circ} \mathrm{C}$, the plate was inspected for growth of colonies, where growth of even a single colony is indicative of resistance (Hackberth and Chambers, 1989). The above test results were further confirmed by a minimum inhibitory concentration (MIC) testing, which was determined by the plate micro-dilution method with an oxacillin concentration range of $0.125-256 \mu \mathrm{g} / \mathrm{ml}$ (NCCLS, 2003), or by an $E$-test (AB BIODISK, Solna, Sweden) where the oxacillin $E$-test strip was placed onto Mueller-Hinton plate supplemented with $2 \% \mathrm{NaCl}$, then incubated at $35^{\circ} \mathrm{C}$ for $24 \mathrm{~h}$. Oxacillin resistance was defined as $E$-test MICs of $\geq 4 \mu \mathrm{g} / \mathrm{ml}$.

\subsection{Staphylococcal enterotoxin detection}

A commercial RPLA test kit, SET-RPLA (Denka Seiken, Tokyo, Japan) detecting staphylococcal enterotoxins A, B, C, D and E, was available for the study. Standard S. aureus enterotoxins A, B, C, D and $\mathrm{E}$ were used as positive controls and latex as the negative control. Agglutination result was observed with transmitted light through the bottom of the plate after $16 \mathrm{~h}$ of incubation (Fujikawa and Igarashi, 1988).

\subsection{DNA purification for PCR amplification}

Total genomic DNA was obtained from $S$. aureus by PUREGENE DNA purification kit (Gentra, Minneapolis, MN). Five main steps including cell lysis, RNase treatment, protein precipitation, DNA precipitation and DNA hydration were performed according to the manufacturer's protocol. The purified DNA was stored at $4{ }^{\circ} \mathrm{C}$ before use.

\subsection{Multiplex PCR}

Multiplex polymerase chain reaction (PCR) was designed to detect five staphylococcal enterotoxin (SE) genes-sea, seb, $\mathrm{sec}_{2}$, sed and see in this study. Two novel universal primers (U1: CCAACGTTTTAGCAGAGAAG and U2: TTGCGTAAAAAGTCTGAATT), which encode consensus sequences, and five specific primers (A2: ATTAACCGAAGGTTCTGTAGA， B2: TTTTTCTTTGTCGTAAGATAA， C2: TAAGTTCCCATTATCAAAGTG, D2: TAATGCTATATCTTATAGGG and E2: TAAACCAAATTTTCCGTG) were selected, each encoding unique sequences for toxin genes. Five primers pairs including U2/ A2, U1/B2, U1/C2, U2/D2 and U2/E2 were then used in multiplex PCR for detecting culture mixture of different $S$. aureus strains (Wang et al., 2002b). Each primer was specific for the detection of its corresponding toxin gene and none of the specific primer pairs cross-reacted with each other. The sizes of the amplified PCR products were 582, 732, 403, 251 and $474 \mathrm{bp}$ for enterotoxin genes A, B, C, D and E, respectively. Apart from the above five SE genes, an additional nine staphylococcal toxin-specific primers for seg, seh, sei, sek, sel, sem, sen, seo and seq genes were also prepared according to Omoe et al. (2002) and Smyth et al. (2005) to investigate the corresponding SE genes.

\subsection{Epidemiological typing}

ORSA isolates were characterized by pulsed-field gel electrophoresis (PFGE) analysis and multi-locus sequence typing (MLST).

\subsubsection{PFGE typing}

PFGE was performed according to a published protocol (Matushek et al., 1996). Total cellular DNA was extracted using the standard procedure method for preparation of genomic DNA (Matushek et al., 1996). DNA was digested with SmaI (Promega, Madison, WI) and fragments were separated by PFGE using a CHEF DRIII PFGE apparatus (Bio-Rad Laboratories, Hemel Hempstead, UK). Electrophoresis parameters were $6 \mathrm{~V} / \mathrm{cm}$ with an angle of $120^{\circ}$ and switch time of $6.8-$ 
$63.8 \mathrm{~s}$ over $23 \mathrm{~h}$ at $14{ }^{\circ} \mathrm{C}$. The Bio-Profile Image Analysis Software (Vilber Lourmat, Marne la Vallee, France) was used to analyze banding patterns. Pattern differences were interpreted as recommended by Tenover et al. (1995).

\subsubsection{MLST typing}

MLST typing is a nucleotide sequence-based approach to the unambiguous characterization of microorganism strains (Maiden et al., 1998). MLST involves obtaining the sequences of internal fragments of seven house-keeping genes for each strain of a particular species, for example, the seven housekeeping genes $\operatorname{arcC}$, aroE, glpF, gmk, pta, tpi and yqiL were extracted from chromosomal DNA. Chromosomal DNA was extracted according to the method of Enright et al. (2000). The PUREGENE DNA purification kit (Gentra, Minneapolis, $\mathrm{MN}$ ) was used for DNA purification. PCRs were carried out with $50 \mu \mathrm{l}$ reaction volumes containing $0.5 \mu \mathrm{l}$ of chromosomal DNA (approximately $0.5 \mu \mathrm{g}$ ), $0.5 \mu \mathrm{g}$ of each primer, $1 \mathrm{U}$ of Taq DNA polymerase (Qiagen, Crawley, United Kingdom), $5 \mu \mathrm{l}$ of $10 \times$ buffer (supplied with the Taq polymerase), and $0.2 \mathrm{mM}$ deoxynucleoside triphosphates (Applied Biosystems, Foster, CA). The PCR conditions were performed with the following cycling parameters: $95^{\circ} \mathrm{C}$ for $5 \mathrm{~min}$, followed by 30 cycles of $55{ }^{\circ} \mathrm{C}$ for $1 \mathrm{~min}, 72{ }^{\circ} \mathrm{C}$ for $1 \mathrm{~min}$, and $95^{\circ} \mathrm{C}$ for $1 \mathrm{~min}$, followed by a final extension step of $72{ }^{\circ} \mathrm{C}$ for $5 \mathrm{~min}$. The ABI3730XL DNA sequencer (Applied Biosystems) with GeneMapper v3.2 software was used for nucleotide sequencing. The results, sequence type (ST) patterns, were assigned by using the MLST database (http:// www.mlst.net).

\subsection{Statistical analysis}

Calculation of statistical significance was performed with the Chi-square test for categorical variables $(P$ value of $<0.05$ was considered significant). Sensitivity, specificity and kappa coefficient (kappa value) were used to measure the agreement between diagnostic tests using PCR as the gold standard. The kappa statistic, defined as the proportion of potential agreement beyond chance exhibited by two or more tests, is calculated by the method of marginal cross products. The value of kappa ranges from -1.0 (perfect disagreement) through
0.0 (chance agreement only) to +1.0 (perfect agreement) (Sackett, 1992).

\section{Results}

This study analyzed 600 suspected Staphylococci isolates of animal, environmental, and worker samples from poultry farms, swine herds, dairy farms and one meat market. Of these, a total of 30 ORSA isolates were identified (Table 1).

According to the results of RPLA, 15 strains were characterized successfully with a dominance of type $B$ (9) and the remaining type $C$ (6). The screening results of multiplex PCR with five SE genes - sea, seb, $\mathrm{sec}_{2}$, sed and see, types of enterotoxin production can be identified in 18 ORSA isolates where type B (7) was the most common type, followed by type $C$ (4), type A\&B-showing both $\mathrm{A}$ and $\mathrm{B}$ bands simultaneously (3), type A (2), and type C\&D - showing both $\mathrm{C}$ and $\mathrm{D}$ bands simultaneously (2). None of the RPLA positive strains were PCR negative. SE detection showed that three types of $A \& B$ isolates and two types of C\&D isolates were detected by multiplex PCR (Table 1), but only two of them were type B and the other two were type C, analyzed by RPLA, respectively. Statistical analysis showed multiplex PCR and RPLA approaches were indifferent in terms of SE detection. Sensitivity and specificity of RPLA were $61.1 \%$ and $100 \%$, respectively, by taking PCR as the gold standard, while consistency reached a level of moderate agreement (kappa value 0.57). If type $A \& B$ strains were treated as type A or type B strains instead, multiplex PCR and RPLA had a statistical difference for SE detection, and the sensitivity and specificity of RPLA became $83.3 \%$ and $100 \%$ reaching a consistency level of substantial agreement (kappa value 0.80 ). Detection by the additional nine staphylococcal toxin-specific primers to the corresponding seven genes - seg, sek, sel, sem, sen, seo and seq were found. Associated toxin production could not be characterized in nine ORSA isolates (Table 1).

Bacterial phylogenetic relationship of 21 ORSA isolates (19 of which were PCR enterotoxin-gene positive, and the remaining two isolates-17 and 18, had no detectable enterotoxin-gene) were executed and collected for PFGE typing. Five major clusters (cluster I: strains 17 and 18, cluster II: strains 57, 58, 
Table 1

Distribution and characterization of oxacillin minimum inhibition concentration (MIC)—-types of enterotoxin production detection by reversed passive latex agglutination (RPLA) and polymerase chain reaction (PCR) of 30 oxacillin-resistant S. aureus isolates from livestock and a meat market in Taiwan

\begin{tabular}{|c|c|c|c|c|c|}
\hline Isolation no. & Source $^{a}$ & County/area & $\operatorname{MIC}(\mu \mathrm{g} / \mathrm{ml})$ & RPLA & PCR \\
\hline S39 & Human (S) & Taoyuan & $>256$ & - & $\mathrm{A} / \mathrm{B} / \mathrm{K}$ \\
\hline $\mathrm{C} 17$ & Human (C) & Yunlin & 16 & $\mathrm{~B}$ & $\mathrm{~A} / \mathrm{B} / \mathrm{K} / \mathrm{Q}$ \\
\hline $\mathrm{C} 27$ & Floor surface $(\mathrm{C})$ & Changhua & $>256$ & - & $\mathrm{K}$ \\
\hline $\mathrm{C} 37$ & Human $(\mathrm{C})$ & Yunlin & $>256$ & - & A \\
\hline $\mathrm{C} 47$ & Human (C) & Pingtung & 8 & - & - \\
\hline $\mathrm{C} 87$ & Feed $(\mathrm{C})$ & Yunlin & 128 & - & A \\
\hline C149 & Feed $(\mathrm{C})$ & Tainan & 8 & - & - \\
\hline $\mathrm{C} 161$ & Human (C) & Chiayi & 64 & $\mathrm{~B}$ & $\mathrm{~B} / \mathrm{K} / \mathrm{Q}$ \\
\hline $\mathrm{C} 165$ & Human $(\mathrm{C})$ & Chiayi & 64 & B & $\mathrm{B} / \mathrm{K} / \mathrm{Q}$ \\
\hline $\mathrm{C} 180$ & Human (C) & Yunlin & 128 & $\mathrm{~B}$ & $\mathrm{~B} / \mathrm{K} / \mathrm{Q}$ \\
\hline $\mathrm{C} 186$ & Human (C) & Chiayi & 6 & B & $\mathrm{B}$ \\
\hline HR2 & Human $(\mathrm{H})$ & Hualien & 6 & $\mathrm{~B}$ & $\mathrm{~A} / \mathrm{B} / \mathrm{K}$ \\
\hline $\mathrm{T} 4$ & Human $(\mathrm{M})^{\mathrm{b}}$ & Taoyuan & 16 & - & - \\
\hline $\mathrm{T} 18$ & $\operatorname{Human}(\mathrm{M})^{\mathrm{b}}$ & Taoyuan & 6 & - & $\mathrm{G}$ \\
\hline $\mathrm{T} 21$ & $\operatorname{Human}(\mathrm{M})^{\mathrm{b}}$ & Taoyuan & 6 & - & - \\
\hline $\mathrm{T} 28$ & Human $(\mathrm{M})^{\mathrm{b}}$ & Taoyuan & 6 & $\mathrm{C}$ & $\mathrm{C}$ \\
\hline $\mathrm{T} 32$ & Human $(\mathrm{M})^{\mathrm{b}}$ & Taoyuan & 6 & $\mathrm{C}$ & $\mathrm{C} / \mathrm{L}$ \\
\hline $\mathrm{T} 51$ & $\operatorname{Human}(\mathrm{M})^{\mathrm{b}}$ & Taoyuan & 8 & $\mathrm{~B}$ & B \\
\hline T54 & Human $(\mathrm{M})^{\mathrm{b}}$ & Taoyuan & $>256$ & - & - \\
\hline T55 & Human $(\mathrm{M})^{\mathrm{b}}$ & Taoyuan & 6 & $\mathrm{C}$ & $\mathrm{C} / \mathrm{G}$ \\
\hline T68 & Human $(\mathrm{M})^{\mathrm{b}}$ & Taoyuan & 48 & - & $\mathrm{M} / \mathrm{O}$ \\
\hline $\mathrm{T} 70$ & Human $(\mathrm{M})^{\mathrm{b}}$ & Taoyuan & 12 & - & - \\
\hline $\mathrm{T} 71$ & Human $(\mathrm{M})^{\mathrm{b}}$ & Taoyuan & 6 & $\mathrm{C}$ & $\mathrm{C}$ \\
\hline 17 & Human $(\mathrm{M})^{\mathrm{c}}$ & Taoyuan & 8 & - & - \\
\hline 18 & Human $(\mathrm{M})^{\mathrm{c}}$ & Taoyuan & 6 & - & - \\
\hline 43 & Human $(\mathrm{M})^{\mathrm{c}}$ & Taoyuan & 128 & - & - \\
\hline 55 & Human $(\mathrm{M})^{\mathrm{c}}$ & Taoyuan & 128 & $\mathrm{C}$ & $\mathrm{C} / \mathrm{D} / \mathrm{G} / \mathrm{O} / \mathrm{N}$ \\
\hline 56 & Human $(\mathrm{M})^{\mathrm{c}}$ & Taoyuan & 6 & $\mathrm{C}$ & $\mathrm{C} / \mathrm{D}$ \\
\hline 57 & $\operatorname{Human}(\mathrm{M})^{\mathrm{c}}$ & Taoyuan & 16 & $\mathrm{~B}$ & B \\
\hline 58 & Human $(M)^{c}$ & Taoyuan & 6 & B & $\mathrm{B}$ \\
\hline
\end{tabular}

${ }^{\text {a }}$ C: poultry farm; H: swine herd; M: meat market; S: bovine herd.

b Isolated from 2004.

c Isolated from 2005.

C161, T51, C17, S39, C37 and C180; cluster III: strains T28, T32 and C165; cluster IV: strains 55, 56, T55 and T71; cluster V: strains C27, C87, HR2 and T18) were suggested (Fig. 1). The results showed a wide diversity of PFGE patterns among the isolates from different subject populations. Among these clusters, $14(66.7 \%)$ isolates were distinguishable at the $65 \%$ similarity level. Additionally, two set of strains (strains 55 and 56, strains 57 and 58) were clustered with $100 \%$ homology as well as the other two clusters (strains 17 and 18, strains C17, S39, C37) with $>80 \%$ homology. Strains 17, 18, 55, 56, 57 and 58 were all from the same meat market in Taoyuan County.
Among MLST typing, 15 ORSA isolates were categorized into seven ST patterns (ST12, ST15, ST9, ST59, ST121, ST338 and ST508) (Fig. 1). For the other six ORSA isolates, one was thought to have a single-locus variant (slv) with alleles differing only at the aro locus (allele 3) of ST9; three others also had a single-locus variant (slv), but with alleles differing only at the gmk locus (allele 48) of ST338; the remaining two isolates could not be characterized. The major prevalent types of isolates were ST338/ST338 $_{\text {slv }}$ (6) and ST59 (4); the others were ST508 (3), ST12 (2), ST9/ST9slv (2), ST15 (1) and ST121 (1). Multiple clones of ORSA were thus suggested. 


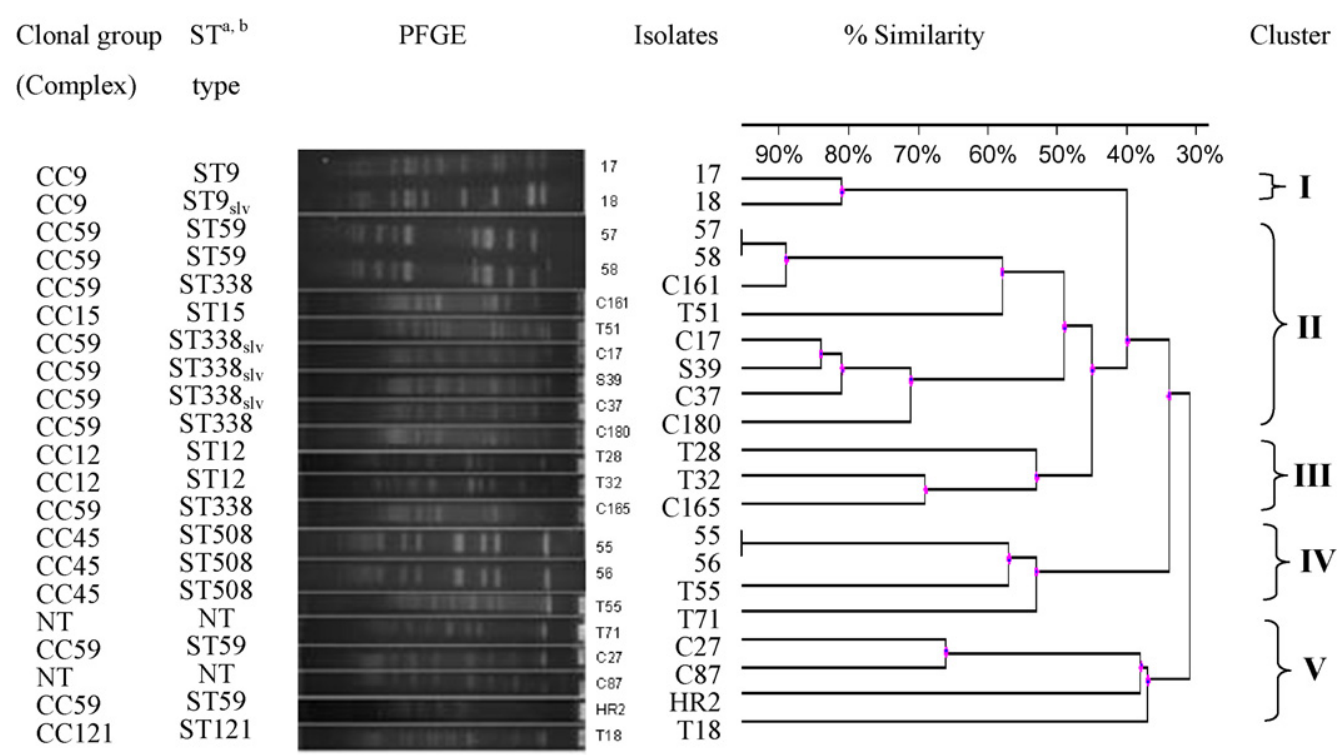

Fig. 1. Phylogenetic dendrogram (\% similarity) of 21 ORSA isolates (19 of which were enteroroxin-gene positive ORSA and two were nondetectable enterotoxin-gene ORSA isolates) collected for PFGE typing with SmaI digestion and ST determined based on the MLST website (http://saureus.mlst.net/): (a) NT, non-typeable; (b) ST9slv and ST338slv, a single-locus variant (slv) of ST239 and ST338.

Population genetic studies based on MLST have shown that major ORSA clones have emerged from six clonal complexes (CCs), as shown in Fig. 1. The predominant clonal complex was CC59 (10) with both ST59 and ST338; the rest were CC45 (3), CC12 (2), CC9 (2), CC15 (1) and CC121 (1). Upon comparison against the MLST database, the obtained dendrogram indicated that the levels of genetic relatedness within this ST pattern set of 15 ORSA isolates were assigned (Fig. 2).

\section{Discussion}

A total of 30 ORSA isolates were identified by use of the screening plate test and $27(90.0 \%)$ of these strains were from human sources (Table 1). Human subjects therefore play a major role in potential ORSA contaminations.

Some PCR-positive isolates did not show detectable products upon RPLA. These might be due to toxin production below the detection limit of the RPLA assay or to the non-expression of genes or to detection of genes that does not necessarily indicate production and biological activity of the toxins (da Cunha et al., 2007). The detection limit of RPLA is about $0.5 \mathrm{ng}$ of SE per $\mathrm{ml}\left(1.5 \times 10^{6} \mathrm{CFU}\right)$ while the analytical sensitivity of the PCR assay for enterotoxin genes is approximately 250-1000 CFU (Klotz et al., 2003). PCR is thus more efficient for the detection of SE than the agglutination assay (SET-RPLA). Our data showed that the detection of SEB and SEC were genotypically and phenotypically identical but not for SEA. Apart from the fact that SEB and SEC are easily secreted in greater amount than other SEs, SEA is produced in the log phase of growth while the cultures used for RPLA were in the stationary phase. That is why SEA is detected by genotype testing (PCR) but not RPLA, and since SEB and SEC are produced during the transition from the exponential to the stationary phase of growth, making it feasible for RPLA detection. Another possibility was that a new $S$. aureus enterotoxin producing strain with type $\mathrm{A} \& \mathrm{~B}$ or type $C \& D$ coincidentally may have increased sensitivity and caused different RPLA kappa values. There were 21 ORSA enterotoxin-gene isolates that were identified with 14 multiplex PCR gene detections, since PCR results can pinpoint the enterotoxin genes of the test bacteria but not their correspondence enterotoxin proteins. The necessity of future research in purification of these SEs may be important in order to elucidate other food-poisoning incidences caused by $S$. aureus apart from enterotoxin $\mathrm{A}$ to $\mathrm{E}$. 


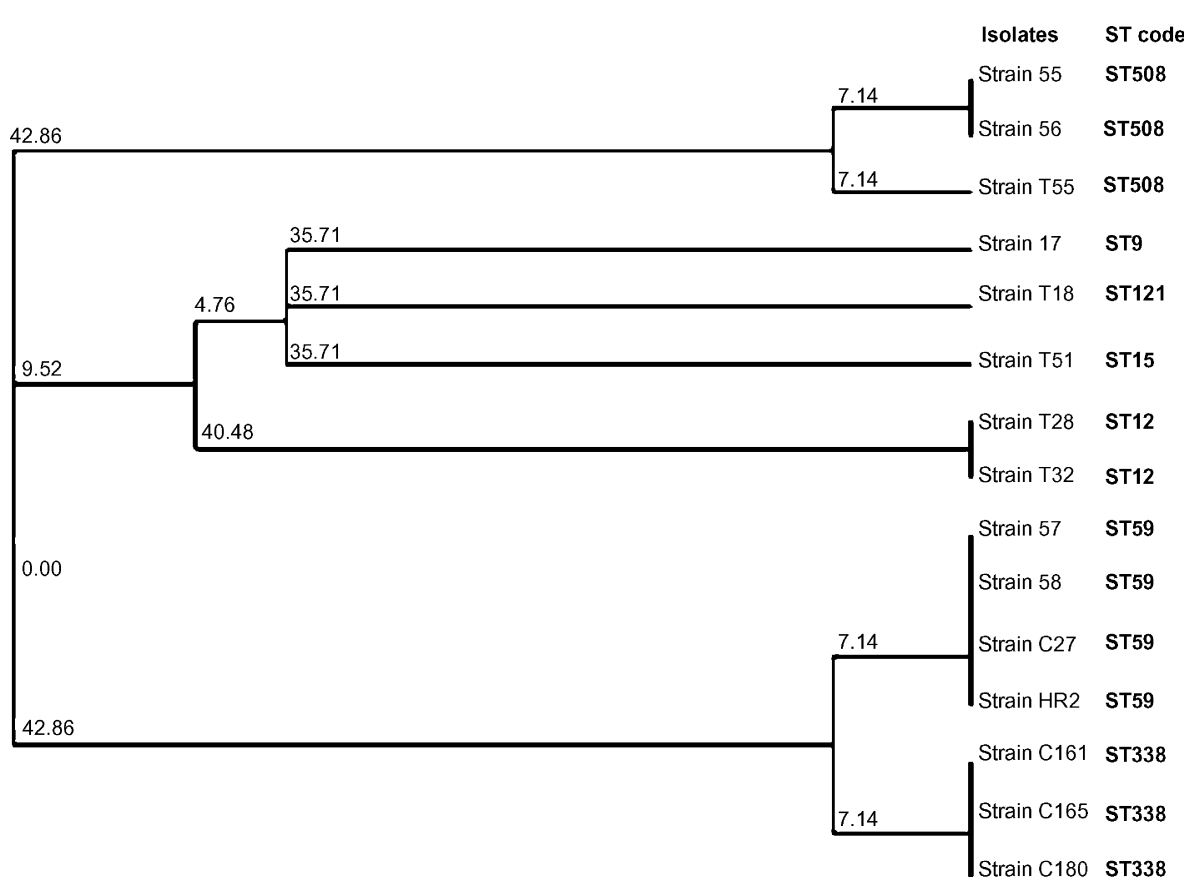

Fig. 2. Dendrogram (Neighbour Joining Tree) showing the levels of similarity between sequence type (ST) patterns of 15 ORSA isolates were assigned using the MLST database (http://www.mlst.net); 14 of which were PCR enteroroxin-positive, and the remaining isolate (17) had no detectable enterotoxin. There are seven ST patterns and the scale indicates levels of genetic relatedness within this set of isolates.

PFGE results indicated that genetic similarity from human source strains collected at poultry farm was high. In cluster II, strain C17 and C37 were identified from the same poultry farm but cultured from different workers in Yunlin County, where both strains had genetic similarity of $>80 \%$. C180 was also from the same county but cultured at a different poultry farm. These identities support a probable assumption that the above-mentioned ORSA may share possible crosscontamination potential due to crowded and closed water-cooled roosting environments. Thus, the livestock facility may play an important role in nearby community colonization within the local geographical area. When typing with PFGE, strain C186 - an enterotoxin-positive strain for both RPLA and PCR showed weak and ambiguous bands and also did not match any current ST pattern of MLST analysis. We suggest that there was probably another better restriction enzyme than SmaI for DNA fragments separation, or C186 may be a new ORSA that requires additional MLST genes analysis.

Based on MLST and SCCmec typing, two distinct genotypes of MRSA strains have been identified in
Asia (Ko et al., 2005). CC5-MRSA-II is a prototype clone in Korea and Japan while CC239-MRSA-III (or IIIA) is a major clone in other Asian countries. In this study, seven ST patterns were distinguished. The major types, ST338/ST338 slv and ST59, were both highly prevalent in Taiwan's inpatient and outpatient hospital settings (Chen and Huang, 2005). Since ST59 and ST338 are emerging in humans at livestock facilities in Taiwan, we suggest that ST59 and ST338 are transmissible and may prevail between HA-MRSA and CA-MRSA strains and thus result in potential drug resistance in different human societies. In addition, MLST can allow strain comparison studies by different groups and local database can be established for long-term epidemiological research. These data thus demonstrated a unique geographical distribution of major genotypes of MRSA clones in the Asian region in relation to other global MRSA clones. Of these, ST59 was observed in the United States (Vandenesch et al., 2003) and ST338/ST338 $8_{\text {slv }}$ were also recognized by Chen et al. (2005) in Taiwan (ST388 was reclassified as ST338 according to personal communication with Chen). 
The predominant epidemic clones of MRSA in North America were ST247 (Canada-MRSA-1 and USA500) and ST5 (Canada-MRSA-2 and USA100) (McDougal et al., 2003; Simor et al., 2005); neither ST247 nor ST5 were detected in our study. In Asian countries, the major ST patterns are ST5 (Korea and Japan), ST59 (Taiwan), ST239 (China, India, Indonesia, Singapore, Sri Lanka, Thailand and Vietnam) and ST241 (India, Philippines, Saudi Arabia, Taiwan, Thailand and Vietnam) (Ko et al., 2005). While ST5 and ST59 each belonged to CC5 and CC59, most MRSA isolates (ST239 and ST241) from other Asian countries belonged to CC239. Regarding Western countries, the major ST patterns are ST1 (US), ST5 (US and Canada), ST8 (US, Canada, Scotland, Ireland, Australia, UK, Germany, Netherlands and France), ST30 (UK, Spain and Germany), ST36 (US), ST80 (France, Switzerland and Greece) and ST247 (USA and Canada) (McDougal et al., 2003; Simor et al., 2005; Vandenesch et al., 2003), and they belong to five major clonal complexes: CC1 (ST1), CC5 (ST5), CC30 (ST30), CC80 (ST80) and CC239 (ST8 and ST247). There seems to be two unique geographic distribution and evolutionary patterns for MRSA clones between Asia and Europe-USA. In the eBURST diagrams of MLST database, ST8, ST239 and ST247 all belong to CC239 group. Since ST8 is the founder and ST239 is the subgroup founder, we suggested that USA and European countries were the origin of CA-MRSA with the ST8 pattern (Vandenesch et al., 2003), which then probably transferred to the subsequent ST239 pattern after several generations and became an epidemic strain in Asian countries. Another possibility is that these two patterns have a common ancestor.

\section{Conclusions}

The results of this study provided molecular typing and epidemiological study of staphylococcal enterotoxin and ORSA isolates from livestock facilities in Taiwan. The study suggests the need for continuous monitoring of ORSA and staphylococcal enterotoxinproducing strains in workers at farms and meat markets, and the need to analyze the relationship between environment, human and animals to trace the epidemiological evidence of CA-MRSA and HAMRSA in human living environments.

\section{Acknowledgments}

This study was supported by grant 93AS-8.2.2-ADU1 (5) from the Council of Agriculture, Taiwan and the Veterinary Hospital of National Taiwan University. We also thank the Bureau of Food and Drug Analysis and also National Health Research Institutes for their assistance.

\section{References}

Ayliffe, G.A.J., Buckles, A., Casewell, M.W., Cookson, B.D., Cox, R.A., Duckworth, G.J., French, G.L., Griffiths-Jones, A., Heathcock, R., Humphreys, H., et al., 1998. Revised guidelines for the control of methicillin-resistant Staphylococcus aureus infection in hospitals: report of a combined working party of the British Society for Antimicrobial Chemotherapy, the Hospital Infection Society and the Infection Control Nurses Association. J. Hosp. Infect. 39, 253-290.

Bennett, R.W., Lancette, G.A., 1998. Staphylococcus aureus (Ch. 12)In: Food and Drug Administration Bacteriological Analytical Manual. 8th ed. (Revision A) AOAC International, Gaithersburg, MD.

Centers for Disease Control and Prevention (CDC)., 1999. Four pediatric deaths from community-acquired methicillin-resistant Staphylococcus aureus. Minnesota and North Dakota, 19971999. Morb. Mortal. Wkly. Rep. 48, 707-710.

Chen, R.S., 2005. Analysis of Staphylococcal enterotoxins from workers- and livestock animals-isolates in Chinese with English abstract. Master Thesis. Graduate Institute of Veterinary Medicine, National Taiwan University, Taiwan.

Chen, C.J., Huang, Y.C., 2005. Community-acquired methicillinresistant Staphylococcus aureus in Taiwan. J. Microbiol. Immunol. Infect. 38, 376-382.

Chen, F.J., Lauderdale, T.L., Huang, I.W., Lo, H.J., Lai, J.F., Wang, H.Y., Shiau, Y.R., Chen, P.C., Ito, T., Hiramitsu, K., 2005. Methicillin-resistant Staphylococcus aureus in Taiwan. Emerg. Infect. Dis. 11, 1760-1763.

da Cunha, M.L., Calsolari, R.A.O., Araújo, J.P., 2007. Detection of enterotoxin and toxic shock syndrome toxin 1 genes in Staphylococcus, with emphasis on coagulase-negative staphylococci. Microbiol. Immunol. 51, 381-390.

de Sousa, M.A., Crisóstomo, M.I., Sanches, I.S., Wu, J.S., Fuzhong, J., Tomasz, A., de Lencastre, H., 2003. Frequent recovery of a single clonal type of multidrug-resistant Staphylococcus aureus from patients in two hospitals in Taiwan and China. J. Clin. Microbiol. 41, 159-163.

Devriese, L.A., Vandamme, L.R., Fameree, L., 1972. Methicillin (cloxacillin)-resistant Staphylococcus aureus strains isolated from bovine mastitis cases. Zbl. Vet. B. 19, 598-605.

European Antimicrobial Resistance Surveillance System (EARSS) Annual Report, 2005. Antimicrobial resistance in Europe. Ch. 4, pp. 43-46. 
Enright, M.C., Day, N.P., Davies, C.E., Peacock, S.J., Spratt, B.G., 2000. Multilocus sequence typing for characterization of methicillin-resistant and methicillin-susceptible clones of Staphylococcus aureus. J. Clin. Microbiol. 38, 1008-1015.

Fujikawa, H., Igarashi, H., 1988. Rapid latex agglutination test for detection of staphylococcal enterotoxins A to E that uses highdensity latex particles. Appl. Environ. Microbiol. 54, 2345-2348.

Hackberth, C.J., Chambers, H.F., 1989. Methicillin-resistant staphylococci: detection methods and treatment of infections. Antimicrob. Agents Chemother. 33, 995-999.

Kim, H.B., Park, W.B., Lee, K.D., Choi, Y.J., Park, S.W., Oh, M., Kim, E.C., Choe, K.W., 2003. Nationwide surveillance for Staphylococcus aureus with reduced susceptibility to vancomycin in Korea. J. Clin. Microbiol. 41, 2279-2281.

Klotz, M., Opper, S., Heeg, K., Zimmermann, S., 2003. Detection of Staphylococcus aureus enterotoxins A to D by real-time fluorescence PCR assay. J. Clin. Microbiol. 41, 4683-4687.

Ko, K.S., Lee, J.Y., Suh, J.Y., Oh, W.S., Peck, K.R., Lee, N.Y., Song, J.H., 2005. Distribution of major genotypes among methicillinresistant Staphylococcus aureus clones in Asian countries. J. Clin. Microbiol. 43, 421-426.

Ma, Y.P., Chang, S.K., Chou, C.C., 2006. Characterization of bacterial susceptibility isolates in sixteen dairy farms in Taiwan. J. Dairy Sci. 89, 4573-4582.

Maiden, M.C., Bygraves, J.A., Feil, E., Morelli, G., Russell, J.E., Urwin, R., Zhang, Q., Zhou, J., Zurth, K., Caugant, D.A., Feavers, I.M., Achtman, M., Spratt, B.G., 1998. Multilocus sequence typing: a portable approach to the identification of clones within populations of pathogenic microorganisms. Proc. Natl. Acad. Sci. U.S.A. 6, 3140-3145.

Matushek, M.G., Bonten, M.J., Hayden, M.K., 1996. Rapid preparation of bacterial DNA for pulsed-field gel electrophoresis. J. Clin. Microbiol. 34, 2598-2600.

McDougal, L.K., Steward, C.D., Killgore, G.E., Chaitram, J.M., McAllister, S.K., Tenover, F.C., 2003. Pulsed-field gel electrophoresis typing of oxacillin-resistant Staphylococcus aureus isolates from the United States: establishing a national database. J. Clin. Microbiol. 41, 5113-5120.

National Committee for Clinical Laboratory Standards (NCCLS), 2003. Performance Standards for Antimicrobial Disk Susceptibility Tests. Approved Standard, 8th ed., Wayne, PA.

O'Mahony, R., Abbott, Y., Leonard, F.C., Markey, B.K., Quinn, P.J., Pollock, P.J., Fanning, S., Rossney, A.S., 2005. Methicillinresistant Staphylococcus aureus (MRSA) isolated from animals and veterinary personnel in Ireland. Vet. Microbiol. 109, 285-296.
Omoe, K., Ishikawa, M., Shimoda, Y., Hu, D.L., Ueda, S., Shinagawa, K., 2002. Detection of seg, seh, and sei genes in Staphylococcus aureus isolates and determination of the enterotoxin productivities of $S$. aureus isolates Harboring seg, seh, or sei genes. J. Clin. Microbiol. 40, 857-862.

Sackett, D.L., 1992. A primer on the precision and accuracy of the clinical examination. J. Am. Med. Assoc. 267, 2638-2644.

Simor, A.E., Ofner-Agostini, M., Gravel, D., Varia, M., Paton, S., McGeer, A., Bryce, E., Loeb, M., Mulvey, M., 2005. Surveillance for methicillin-resistant Staphylococcus aureus in Canadian hospitals-A report update from the Canadian Nosocomial Infection Surveillance Program. Can. Commun. Dis. Rep. 31, 33-40.

Smyth, D.S., Hartigan, P.J., Meaney, W.J., Fitzgerald, J.R., Deobald, C.F., Bohach, G.A., Smyth, C.J., 2005. Superantigen genes encoded by the $e g c$ cluster and SaPIbov are predominant among Staphylococcus aureus isolates from cows, goats, sheep, rabbits and poultry. J. Med. Microbiol. 54, 401-411.

Tenover, F.C., Arbeit, R.D., Goering, R.V., Mickelsen, P.A., Murray, B.E., Persing, D.H., Swaminathan, B., 1995. Interpreting chromosomal DNA restriction patterns produced by pulsed-field gel electrophoresis: criteria for bacterial strain typing. J. Clin. Microbiol. 33, 2233-2239.

Van, D.E., Wolfhagen, M.J., Box, A.T., Heck, M.E., Wannet, W.J., Fluit, A.C., 2004. Human-to-dog transmission of methicillinresistant Staphylococcus aureus. Emerg. Infect. Dis. 10, 22352237.

Vandenesch, F., Naimi, T., Enright, M.C., Lina, G., Nimmo, G.R., Heffernan, H., Liassine, N., Bes, M., Greenland, T., Reverdy, M.E., Etienne, J., 2003. Community-acquired methicillin-resistant Staphylococcus aureus carrying Panton-Valentine leukocidin genes: worldwide emergence. Emerg. Infect. Dis. 9, 978984.

Wang, J.T., Chen, Y.C., Yang, T.L., Chang, S.C., 2002a. Molecular epidemiology and antimicrobial susceptibility of methicillinresistant Staphylococcus aureus in Taiwan. Diagn. Microbiol. Infect. Dis. 42, 199-203.

Wang, S.J., Chow, L.W., Wu, M.J., 2002b. Multiplex PCR for the simultaneous detection of the sea, seb, sec, sed and see genes of enterotoxigenic Staphylococcus aureus. J. Food Drug Anal. 10, 164-169.

Weese, J.S., Archambault, M., Willey, B.M., Hearn, P., Kreiswirth, B.N., Said-Salim, B., McGeer, A., Likhoshvay, Y., Prescott, J.F., Low, D.E., 2005. Methicillin-resistant Staphylococcus aureus in horses and horse personnel 2000-2002. Emerg. Infect. Dis. 11, 430-435. 